\title{
CHANGE LIFE TO ONLINE: PEDAGOGICAL RELATIONSHIP IN PANDEMIC TIME
}

\author{
Ana Mouraz, Ana Nobre, Universidade Aberta, Portugal
}

\section{Abstract}

Suddenly, the distance education system, which had been created to reach audiences traditionally without access to on-site teaching offers, became the norm. Teachers and Schools had to face this important question from day to night: how to continue to educate, share knowledge, help students and motivate them in the construction of knowledge? The purpose of this communication is to reflect on the effects of the schools closure, due to pandemic, on the pedagogical practices of teachers, namely on the pedagogical relationship. 59 Portuguese teachers of basic and secondary education were questioned, in a casual sample, but diversified in terms of the subjects they teach.

The data obtained allow to conclude that despite all the constraints, the pedagogical relationship was maintained and even came out reinforced from the confinement experience.

\section{Introduction}

Today, in the pandemic situation, educational activity was forced to mobilize to respond to a huge social demand. Distance learning has been a resource to answer, not to the traditional intentions of this type of offer (increase the qualification of the workforce, find new audiences and market segments, etc.), (Mouraz \& Nobre, forthcoming), but to a social demand that stems directly from the constraints imposed by the states. Such demand has been addressing the question: how to continue to educate, share knowledge, help students and motivate students in the construction of knowledge?

Peraya and Peltier (2020) recall how the pedagogical practices with digital technologies and the individual and collective practices of students and teachers were questioned many times during the first confinement due to the pandemic-COVID-19. In just a few days, developments and changes that seemed to take years have accelerated dramatically.

In the spring of 2020, all kindergartens, basic and secondary schools and higher education institutions, in Portugal and worldwide, had to change, in a few days, to distance 
education. The schools were closed, the face-to-face classes were cancelled. Surprisingly, most Portuguese, European and global institutions have gone from massive presence to massive detachment, in all senses of the word: geographical distance, physical distance, relational distance and cognitive distance from reality. (Nobre et al, 2021)

Finding out the dimensions and thinking about the scope of this drastic change has been the work of many researchers in the humanities and educational sciences this year that we have a pandemic situation.

\section{Anthropological Effects}

Teaching activity, at the forefront of our educational systems, currently faces an unprecedented social and anthropological dynamic, associated with technological acceleration, already well underway. This new dynamic will certainly lead to a longawaited and expected paradigm shift in teaching and learning (Devinney \& Dowling, 2020).

Philosopher Claire Marin (2020), an expert on individual and collective changes and disruptions, wrote that "in the face of a disaster, we feel reassured by considering it as a parenthesis rather than a warning ", the warning of 'an imbalance, a rupture, a transition or a transformation. For this philosopher, the experience of the pandemic and its implications (cataclysmic return of great fear) and massive (more than half of humanity confined for long months) is an experience with a very strong destructive potential in the psychic, moral, political, social dimensions and economic, because this experience deconstructs the imaginary constructions, habits, rules of operation and relationships that underlie our societies. Suddenly, all activities directly associated with what we call culture, started to have to exist digitally or to be suspended waiting for the epidemiological control of the pandemic. When they could continue to happen with new and tight rules, which in many cases, accentuated the digital experience of living collectively: could anyone be part of a choir or an orchestra? Could anyone participate in a conference or a political demonstration? Could anyone visit an exhibition or go to the theatre? Could anyone participate in a religious celebration or organize a family or friends party? The answer to the previous questions is, in almost all cases, "yes, one can", but only if this participation is mediated by digital communication technologies. The possibility of being physically with others has strict rules and the new social etiquette promotes the physical distance from others. Changing life online was the motto. What effects does this change have? Historian Françoise Hildesheimer (2020) emphasizes that epidemics play a fundamental role in social, political, economic and sociological development in history. However, their impacts are measured only at the moment of their cessation. Insofar as it is the latter that allows "a 
reversal of the economic situation in all areas" (Hildesheimer, 2020) and opens new way of living. How life can be lived when personal relations are distanced?

\section{Pedagogical effects}

Many schools and teachers developed, before the pandemic, pedagogical work processes in virtual environments (some digital platforms for quizzes, but also for videoconferencing, the virtual classroom, made available by school publishers, or others digital resources, with limited time). Those experiments were running quite well in some schools but were not generalized (Isaías et al, 2017). With the pandemic, these environments were appropriated by the teachers and allowed them to operate a rapid change, without many arrangements, in a very similar way to what they were doing in the classroom (Morgado et al, 2021).

The main concern of teachers and Portuguese schools was to maintain communication with all their students during the school closure (Nobre et al, in press). On the other hand, schools reported the effort to maintain contact with students from the most disadvantaged social groups, using other mechanisms and devices, such as traditional mail or the telephone. Having solved this access (Martins, 2020; OECD, 2020), the next concern was to adapt to the digital dimension what seemed to be the essence of teaching activity. There were many questions from teachers, at all levels of education, that highlighted this concern: What are the main elements of a distance learning course? How should I organize my discipline at a distance? What are the pedagogical practices that I can implement? How do I develop remote assessments? How do I set up remote group work? How to properly articulate the synchronous sessions of the virtual classroom and the asynchronous ones? etc. (Moreira et al, 2020). Through these questions asked everywhere at the same time, the educational community has also experienced its state of emergency.

A revision of the literature, meanwhile published on the effects of the pandemic on pedagogical issues, emphasizes the opportunity, returned by the digital, that education should be centred on the student that learn and less on the teacher that teaches (Doucet, et al, 2020; Pokhrel \& Chhetri, 2021). On the other hand, this inventory also shows an evident difference between the potential of digital as an educational medium and what was put into practice by schools and teachers and was documented in these studies. Thus, some authors find that there has been a transposition from classroom to distance learning rather than a real transition, (Caron, 2020). Others put the change in terms of a reinforcement in the form of creative, handmade, intuitive use of ICT devices, instead of a massive exploration of knowledge and pedagogical practices available and widely studied and used for decades (Nobre, 2018).

One of the specific elements of this attempted transposition stems from the use of synchronous time and the balance between synchronous and asynchronous learning 
activities. At least in the first confinement, and as mentioned by Nobre et al. (forthcoming), schools sought to maintain schedules, often too busy for synchronous classes, as they had not yet realized the increased effort that distance learning carry on.

Three axes summarize the essentials of the pedagogical relationship (Postic, 1984) that are important to transposing to online: the contact time between teachers and each student; the modes of assessment and providing feedback that teachers give students and opportunities to collaborate with classmates. In the particular case of many of the students involved, it is also interesting to question the mediating role of parents and guardians as an element of achieving the pedagogical relationship. The third axis corresponds to opportunities for interaction with colleagues and the development of collaborative work between students, which teachers should encourage (Mendes et al., 2018).

The purpose of this communication is to reflect on the effects of the schools closure, due to pandemic, on the pedagogical practices of teachers, namely on the pedagogical relationship.

\section{Methodology}

From an operational point of view, the axes of analysis will be:

- The main ways of using synchronous time and the support required from parents and $\mathrm{EE}$ in the development of learning tasks.

- The mechanisms used by teachers to make formative assessment, and to give feedback to students.

- The opportunities created by teachers to promote collaborative work among students.

The research takes on a pilot character, since a "traditional" topic is being focused - the pedagogical relationship, but in a completely new circumstance, because the environment of this relationship is online (Moreira et al., 2020). Furthermore, the decision to pursue this online modality to accomplish pedagogical relationship was not a choice of teachers or students. The study follows a mixed methodology, which collected quantitative and qualitative data, from a semi-open questionnaire designed to collect information about the effects of the pandemic on the pedagogical practices of teachers and schools.

59 Portuguese teachers of basic and secondary education were questioned, in a casual sample, but diversified in terms of the subjects they teach.

In this paper we will present data from referred questionnaire, but only regarding the aspects of the pedagogical relationship, as explained above. 
The data were collected through a questionnaire applied digitally via Google forms and were treated in the excel program. The coding of the open responses was done manually.

\section{Results}

\section{Communication modes to assure pedagogical relationship}

An analysis of the Figure 1 shows that the use of digital platforms was the way most frequently mentioned by teachers to maintain the pedagogical relationship with their students. Respondents balanced the synchronous and asynchronous sessions at similar levels. The phone, the WhatsApp network and the use of pre-recorded classes had less frequent or even null expressions.

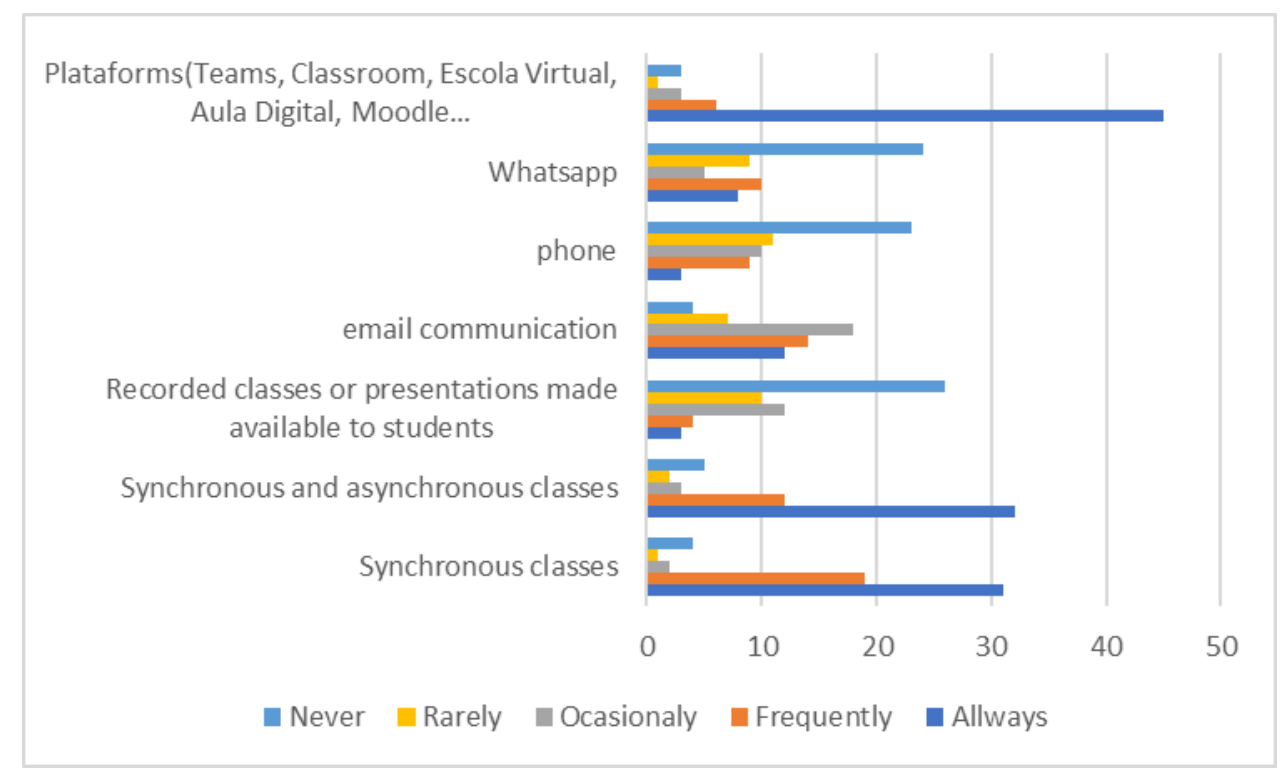

Figure 1. Communication modes to assure pedagogical relationship

The devices used by teachers to do formative assessment, and to give feedback to students

As shown in the Figure 2 and the support required from parents and EE in the development of learning tasks. The feedback given by the teachers happened, especially during synchronous classes. Then, the written forms, whether in the forums, in the mail or other associated forms, were the modalities referred to. 


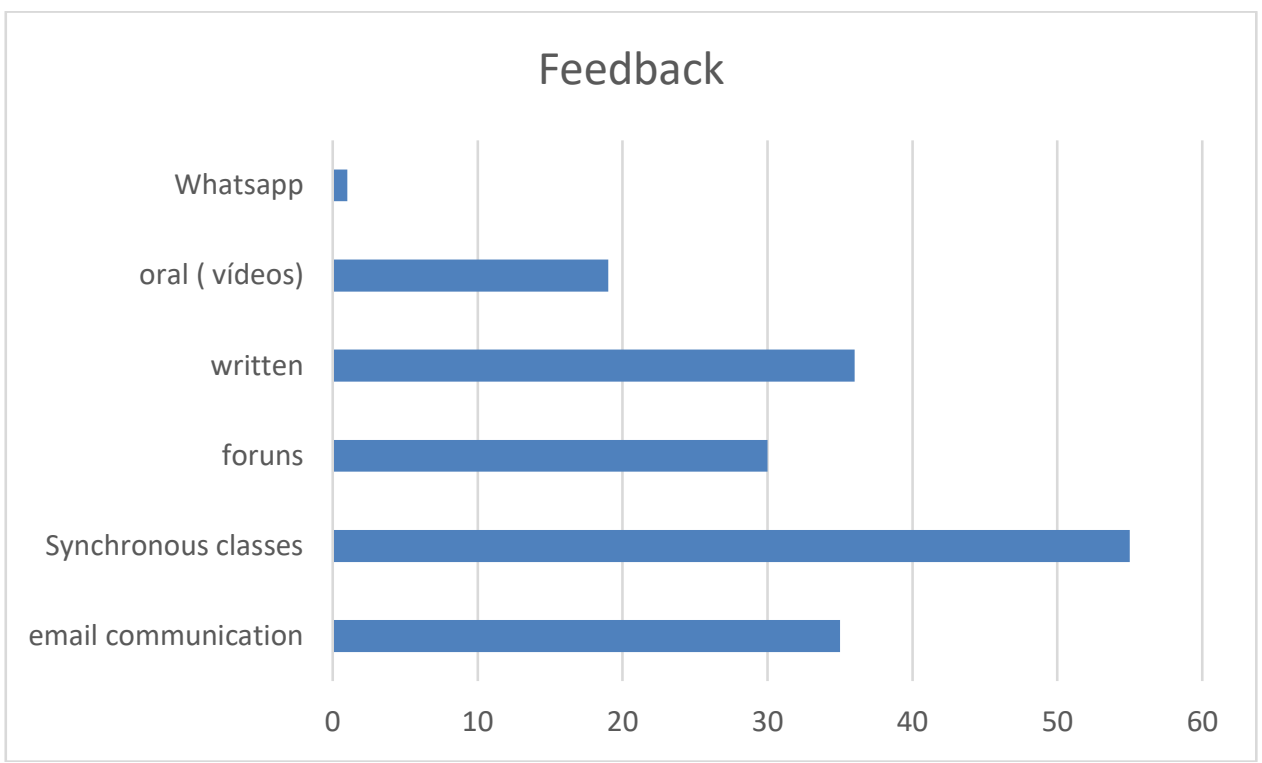

Figure 2. The devices used by teachers to do formative assessment, and to give feedback to students

\section{The opportunities created by teachers to promote collaborative work among students}

Thirty-seven respondents said they had requested group work from their students while twenty-two said they had not done so.

As for the quality of the work developed, it was considered by the teachers to be very good and good (Figure 3).



Figure 3. Quality of collaborative work

Most of the requested collaborative work had the primary intention of promoting discussion among students on the subjects researched and reaching various perspectives. On fewer occasions, group work was used to carry out research work and subsequent presentation of results, in order to encourage collaboration and mutual assistance between students, as well as to promote meaningful learning. Some teachers reported having continued with the work started before school closure. 
When asked about the effects that distance education had on relations with students, there were some testimonies that emphasized distance. However, surprisingly, many teachers found a different proximity to the students, having established bonds that they had not yet developed.

"It allowed for a more open dialogue, both in synchronous sessions and through social networks, since everyone felt the constant need for attention from the teachers and someone who listened to them, listening to the problems they were feeling, due to the learning difficulties and the lack of contact with colleagues and teachers."

At the same time, this proximity is also associated with the fact that students are in their own environment and are more authentic

"In the age group of 10 years there were students who, being in their environments dancing, became much more uninhibited! And with very positive results."

Another effect of this proximity was the knowledge of the reality of each student, namely the family and socio-economic contexts, although it cannot be generalized, several testimonies were collected indicating that this proximity was also established with the families, either because there was more contact, or because more responsibilities were given to them in monitoring the children. Such a situation has occasionally resulted in relationships of greater empathy with families and recognition of the teachers' work, since the parents ended up observing the synchronous classes and the requested work to their children.

\section{Conclusion}

The data obtained show that despite all the constraints, the pedagogical relationship was maintained and even came out reinforced from the confinement experience. The interviewed teachers used mostly synchronous classes, which partially combined with asynchronous activities. It was in this way that they took care of the pedagogical relationship with their students. Despite this option of transposing the presence to synchronous models, the feedback on the tasks performed by the students took place mostly in written form, even though in some cases the forums were chosen to do so. Another idea, identified in the data collected, indicates some redistribution of pedagogical power by parents and EE, whose role and performance seems to have been valued by teachers. However, there is still little information on the long-term effects of these feedlots. A recent OECD study warns of the greater risk that this closure entails for students in 
situations of greater fragility. The hysteresis induced by school closures may be more prevalent among students from less privileged backgrounds. (OECD, 2020)

Baptiste Morizot (2020), reminds us of our interdependence with the world and with others: a learning device can be thought of as a living organism (composed of teachers, students, professionals, etc.) in permanent relationship with the world that the fence and with which the bonds are formed and renewed to feed each other. When the terms of that relationship change and it needs to be feed up in digital environments, it is important to see if that interactive and promoter requirement of the relationship fulfils its function.

\section{References}

Devinney, T., \& Dowling, G. (2020, May 14). Is this the crisis higher education needs to have? Times Higher Education [Blog post]. Retrieved from https://www.timeshighereducation.com/features/crisis-higher-education-needs-have

Doucet, A., Netolicky, D., Timmers, K., \& Tuscano, F. J. (2020). Thinking about pedagogy in an unfolding pandemic (An Independent Report on Approaches to Distance Learning during COVID-19 School Closure). Work of Education International and UNESCO. Retrieved from https://issuu.com/educationinternational/docs/2020_research_covid-19_eng

Hildesheimer, F. (2020, May 15). Cette mondialisation de masse des phénomènes épidémiques, c'est du jamais vu. Le Monde [Blog post]. Retrieved from https://www.lemonde.fr/idees/article/2020/05/15/on-ne-peut-plus-seulement-definir1-epidemie-comme-grand-personnage-archaique-de-1-histoire-dhier_6039718_3232.html

Isaias, P., Reis, F., Coutinho, C., \& Lencastre, J. L. (2017). Empathic technologies for distance/mobile learning: an empirical research based on the Unified Theory of Acceptance and Use of Technology (UTAUT). Interactive Technology and Smart Education, 14(2), 159-180. Retrieved from http://www.emeraldinsight.com/doi/abs/10.1108/ITSE-02-2017-0014.

Martins, S. (2020). A educação e a covid-19: desigualdades, experiências e Impactos de uma pandemia não anunciada. In R. Carmo, I. Tavares, \& A. Cândido (Eds.), Um Olhar Sociológico sobre a Crise Covid-19 em Livro (pp. 37-55). Lisboa: Observatório das Desigualdades, CIES-Iscte.

Mendes, A, Bastos, G, Amante, L, Aires, L., \& Cardoso, T (2018). Modelo Pedagógico Virtual. Cenários de desenvolvimento. Lisboa: Universidade Aberta. 
Moreira, J. A., Henriques, S., Barros, D., Goulão, M. F., \& Caeiro, D. (2020). Educação Digital em Rede: Princípios para o Design Pedagógico em tempos de pandemia. Universidade Aberta, Educação a Distância e elearning, nº 10. Lisboa. ISBN978-972674-881-6. doi 10.34627

Morgado, J. C., Lencastre, J. A., Freires, T., \& Bento, M. (2021). Smart Education as Empowerment: Outlining Veteran Teachers' Training to Promote Digital Migration. Technology, Knowledge and Learning. https://doi.org/10.1007/s10758-021-09494-6

Morizot, B. (2020). Manières d'être vivant. Enquêtes sur la vie à travers nous. Arles : Actes Sud.

Mouraz, A., \& Nobre, A. (forthcoming). Os efeitos da pandemia no desenho e realização de e-atividades no ensino superior. In Educação Superior: (Re)Configurações de um campo em Movimento. Revista Internacional De Educação Superior (RIESUp)”

Nobre, A. (2018). Multimedia technologies and online task-based foreign language teaching-learning. Tuning Journal for Higher Education, 5, 75-97. ISSN-e: 2386-3137.

Nobre, A., \& Mouraz, A. (2020). Reflexões sobre os efeitos da pandemia na aprendizagem digital. In O (Re)inventar da Educação em Tempos de Pandemia. Dialogia. São Paulo, n. 36, p. 367-381, set./dez. 2020

Nobre, A., Mouraz, A., Goulão, M. F., Henriques, S., Barros, D., \& Moreira, J. A. (2021). Docência para a Educação Digital em Rede: Comunicação e Colaboração em Ambientes Virtuais de Aprendizagem. In Revista Praxis.

OECD (2020). The impact of COVID-19 on student equity and inclusion.

Peraya, D., \& Peltier, C. (2020). Ingénierie pédagogique : vingt fois sur le métier remettons notre ouvrage. Distances et médiations des savoirs, 29. Retrieved from http://journals.openedition.org/dms/4817

Pokhrel, S., \& Chhetri, R (2021). A Literature Review on Impact of COVID-19 Pandemic on Teaching and Learning. Higher Education for the Future, 8(1), 133-141. https://doi.org/10.1177/2347631120983481

Postic, M. (1984). Relação Pedagógica. Coimbra: Coimbra Editora. 